\title{
Treatment outcomes after methylphenidate in adults with attention-deficit/hyperactivity disorder treated with lisdexamfetamine dimesylate or atomoxetine
}

\author{
This article was published in the following Dove Press journal: \\ Patient Preference and Adherence \\ 24 March 2016 \\ Number of times this article has been viewed
}

\author{
Alain Joseph' \\ Martin Cloutier ${ }^{2}$ \\ Annie Guérin² \\ Roy Nitulescu ${ }^{2}$ \\ Vanja Sikirica ${ }^{3}$ \\ 'Global HEOR and Epidemiology, \\ Shire, Zählerweg, Zug, Switzerland; \\ ${ }^{2}$ Analysis Group, Inc., Montreal, \\ Quebec, Canada; ${ }^{3}$ Global HEOR and \\ Epidemiology, Shire, Wayne, PA, USA
}

\begin{abstract}
Purpose: To compare treatment adherence, discontinuation, add-on, and daily average consumption (DACON) among adults with attention-deficit/hyperactivity disorder receiving second-line lisdexamfetamine dimesylate (LDX) or atomoxetine (ATX), following methylphenidate.
\end{abstract}

Patients and methods: A retrospective cohort study using US commercial claims databases (Q2/2009-Q3/2013).

Results: At month 12, the LDX cohort $(\mathrm{N}=2,718)$ had a higher adherence level (proportion of days covered: 0.48 versus $0.30, P<0.001$ ) and was less likely to discontinue (Kaplan-Meier estimate: $63 \%$ versus $85 \%, P<0.001)$ than the ATX cohort $(\mathrm{N}=674)$. There were no statistical differences in treatment add-on rates between cohorts (Kaplan-Meier estimate: $26 \%$ versus $25 \%, P=0.297$ ). The LDX cohort had a lower DACON (1.10 versus $1.31, P<0.001)$ and was less likely to have a DACON $>1$ (adjusted odds ratio: $0.20,95 \%$ confidence interval: $0.15-0.25$, $P<0.001)$ than the ATX cohort.

Conclusion: Adults with attention-deficit/hyperactivity disorder treated with LDX following methylphenidate had a higher treatment adherence and lower discontinuation and DACON relative to those treated with ATX following methylphenidate.

Keywords: ADHD, adult, adherence, lisdexamfetamine dimesylate, atomoxetine

\section{Introduction}

Attention-deficit/hyperactivity disorder (ADHD) is a chronic neurobehavioral condition associated with learning disabilities, mood disorders, language disabilities, and disruptive behavior disorders. ${ }^{1,2}$ ADHD is typically diagnosed in childhood and often associated with comorbid conditions, such as sleep and sleep-related breathing disorders, ${ }^{3-10}$ which have been postulated to contribute to the ADHD phenotype ${ }^{11-14}$ (and vice versa ${ }^{15}$ ). ADHD commonly persists into adulthood, ${ }^{2}$ when it may be associated with work-related impairment (eg, changing employer frequently, poor performance, fewer occupational achievements), social-related impairment (eg, lower socioeconomic status, poor driving habits and more frequent car accidents, more frequent use of illegal substances), and relationship-related impairment (eg, more marital problems and higher incidence of separation). ${ }^{16-18}$ Recent systematic literature reviews have estimated the prevalence of ADHD in adults to be $\sim 5 \%$ in Europe, with a similar prevalence in North America $(4.4 \%) .{ }^{19,20}$ Untreated or suboptimally treated adult patients suffering from ADHD are subject to reduced quality of life, psychosocial impairments, and professional
Correspondence: Alain Joseph

Global HEOR and Epidemiology, Shire,

Zählerweg 10, 630। Zug, Switzerland

$\mathrm{Tel}+4|4| 2884390$

Fax +4| 4I 288400 I

Email ajoseph@shire.com
Patient Preference and Adherence 2016:10 391-405

391

Dovepress

http://dx.doi.org/1 0.2147/PPA.S98498 (c) (1) (2) 2016 Joseph et al. This work is published and licensed by Dove Medical Press Limited. The full terms of this license are available at https://www.dovepress.com/terms.php BY NC and incorporate the Creative Commons Attribution - Non Commercial (unported, v3.0) License (http:///creativecommons.org/licenses/by-nc $/ 3.0 /$ ). By accessing the work you
hereby accept the Terms. Non-commercial uses of the work are permitted without any further permission from Dove Medical Press Limited, provided the work is properly attributed. For permission hereby accept the Terms. Non-commercial uses of the work are permitted without any further permission from Dove Medical Press Limited, provided the work is properly attributed. For permission
for commercial use of this work, please see parazraphs 42 and 5 of our Terms (https:/wwww.dovepress com/terms php). 
difficulties. ${ }^{21,22}$ However, although there is scant information in adults, it has been shown that children can alleviate most ADHD-related impairments and enhance their quality of life with currently available treatments.

Stimulants are the standard-of-care first-line pharmacotherapy for adults with ADHD both in Europe and North America. ${ }^{23,24}$ More specifically, methylphenidate (MPH) is the most commonly prescribed first-line treatment for adult patients with ADHD, with generally rare and mild side effects. ${ }^{25-30}$ However, patients may not respond optimally to this treatment or may experience intolerable adverse events. Although little is known about the proportion of adults in such a situation, a systematic literature review among children, adolescents, and adults with ADHD reported that up to $\sim 30 \%$ of patients may face such issues. ${ }^{31,32}$ Several treatment options exist for adult patients who are unresponsive or intolerant to $\mathrm{MPH}$, such as atomoxetine (ATX) and dexamphetamine, or patients may sometimes use other medications that are unlicensed for the treatment of ADHD (eg, bupropion, $\alpha$-adrenergic agents, and tricyclic antidepressants). ${ }^{2,30,33}$ ATX was the first nonstimulant to be approved for the treatment of adults with ADHD in Europe $^{34}$ and is recommended as a second-line therapy for patients who are unresponsive or intolerant to MPH in most European guidelines, including those from the UK's National Institute for Health and Care Excellence. ${ }^{24,35,36}$

Recent studies conducted in adult patients with ADHD in the US compared treatment adherence, ${ }^{37}$ discontinuation, ${ }^{38}$ add-on, and daily average consumption (DACON) ${ }^{39}$ among patients treated in second- or later-line therapy with lisdexamfetamine dimesylate (LDX) and those treated with other commonly prescribed stimulants or ATX. Findings from these studies showed that LDX was associated with statistically significantly higher treatment adherence and lower treatment discontinuation rates compared with ATX. Although not compared between LDX and ATX, treatment add-on rates and DACON were also found to be lower for patients treated with LDX compared with other commonly prescribed long-acting stimulants (ie, osmotic-release oral system MPH, long-acting MPH, and long-acting amphetamine $[\mathrm{AMPH}])$. Findings from previous studies on treatment adherence and discontinuation suggested that these outcomes are of notable importance in ADHD patients from all age groups, as nonadherence or suboptimal adherence and discontinuation are associated with a substantial economic burden and can negatively impact patients' quality of life. ${ }^{40-42}$ Moreover, a recent systematic literature review on adherence, persistence, and treatment discontinuation in patients with ADHD from all age groups found adherence and persistence to ADHD treatments to be inadequate. ${ }^{42}$
Although there are several licensed treatments for adults with ADHD in the US, the European context is quite different, where MPH is the only recommended first-line treatment in most countries and ATX is the most commonly recommended second-line option. ${ }^{30,43}$ Treatment options in most European countries are limited, as highlighted by Retz et al. ${ }^{44}$

More research is needed to understand the potential benefits of commonly indicated ADHD treatments as second-line agents following MPH in the adult ADHD population. ${ }^{2,45-48}$ More specifically, to the best of our knowledge, no studies have focused on second-line treatment outcomes in adults with ADHD who have previously been treated with MPH; that is, in a sample representative of the European context. Therefore, the aim of the current study was to assess the treatment outcomes associated with LDX or ATX in secondline therapy in adult patients with ADHD. More specifically, the aim was to compare treatment adherence, treatment discontinuation, treatment add-ons, and DACON among adult patients treated with LDX versus ATX as second-line options following the use of MPH.

\section{Methods and design}

\section{Data source}

This study was conducted using the Truven Health Analytics MarketScan $^{\circledR}$ (MarketScan) database from 2009 to 2013. The MarketScan database is a US private sector health data resource that reflects the health care experiences of employees and their dependents, as well as Medicare-eligible retirees with employer-provided Medicare supplemental plans covered by the health benefit programs of large employers. All US census regions are represented, although most enrollees are from the South and North Central (Midwest) regions. The database includes health care plan enrollment history and claims for medical (provider and institutional) and pharmacy services. Data were de-identified and comply with the patient confidentiality requirements of the Health Insurance Portability and Accountability Act prior to being delivered to the investigators by a third-party vendor, therefore, according to the authors, no institutional review board approval was required, and they did not apply for an institutional review board ethics approval exemption, or obtain patient consent for this study.

\section{Study sample}

Patients who were initiated on either LDX or ATX as second-line monotherapy between 2009 and 2013, following first-line monotherapy with MPH, were selected from the MarketScan database. To be eligible for the study, all patients were required to have at least one documented diagnosis of ADHD in their medical claims (International Classification 
of Diseases, 9th Revision: 314.0x or 314.9x), have filled at least one prescription for MPH prior to the initiation of LDX or ATX, be continuously enrolled in their health care plan for at least 6 months prior to the initiation of MPH and at least 12 months following the initiation of their second-line therapy (index date), and be at least 18 years old at the index date. Furthermore, a 6-month washout period with no prescription-fills for any stimulants or nonstimulants indicated for ADHD prior to the initiation of MPH was applied, in order to increase the likelihood of selecting patients receiving MPH as their first-line therapy for ADHD.

The study was conducted using a retrospective cohort design. Patients were classified into two mutually exclusive cohorts - the LDX cohort and the ATX cohort - based on the presence of a prescription claim initiated for second-line therapy with one of these agents (index treatment). The baseline period was defined as the 6-month period prior to the index date, and the study period was defined as the 12-month period following the index date.

\section{Outcomes and statistical analyses}

The following patient characteristics, measured on the index date and during the baseline period, are reported for the LDX and ATX cohorts: age on the index date, sex, region of residence, type of health care plan, year of the index date, Charlson comorbidity index, ${ }^{49}$ mental comorbid conditions, ${ }^{50}$ and physical comorbid conditions. ${ }^{51}$ Both physical and mental comorbid conditions were identified based on diagnostic codes documented in claims. Only mental and physical comorbid conditions with at least $2 \%$ prevalence in both cohorts are reported. Statistical comparisons between cohorts were conducted using chi-square tests for categorical variables and Wilcoxon rank-sum tests for continuous variables to identify differences in patient characteristics. A significance level of 0.05 was used in the analyses.

Adherence to the index treatment was measured over the 12-month study period using the proportion of days covered (PDC) and medication possession ratio (MPR). The PDC was calculated as the sum of the number of days with the index treatment during the study period divided by the number of days in the study period (ie, 365 days). The MPR was calculated as the number of days of medication supplied during the study period divided by the number of days in the study period (ie, 365 days). Both the PDC and the MPR are reported as continuous and dichotomous (ie, adherent versus nonadherent) variables. Patients were considered adherent if their PDC/MPR was at least 0.8 and nonadherent otherwise. ${ }^{52}$ Average PDC/MPR levels were compared between the LDX and ATX cohorts using linear regression models, where the dependent variable was the level of adherence (eg, PDC) and the independent variable was a dichotomous variable to identify the patient's cohort (ie, LDX versus ATX). The proportions of adherent patients were compared between cohorts using logistic regression models, where the dependent variable was a binary variable indicating adherence status and the independent variable was a dichotomous variable to identify the patient's cohort. Multivariate regression models adjusted for differences in any discrepant baseline patient characteristics between cohorts. Results are reported as unadjusted and adjusted differences in adherence levels, and as odds ratios (ORs) with 95\% confidence intervals (CIs) and $P$-values.

Treatment discontinuation was defined as a gap of at least 60 consecutive days between the last day of supply of a prescription-fill for the index treatment and the first day of supply of the following prescription-fill for the index treatment or the end of the study period, whichever occurred first. Time to treatment discontinuation was analyzed using survival analyses, with event time defined as the number of days between the index date and first date of treatment discontinuation. Patients' observation periods were censored if patients reached the end of the study period without a treatment discontinuation. The distribution of treatment discontinuation was estimated over time using Kaplan-Meier analyses and compared between cohorts using log-rank tests. Cox proportional-hazards models were used to compare the distribution of treatment discontinuation between cohorts over time, both unadjusted and adjusted for differences in any discrepant baseline patient characteristics. Results are reported as unadjusted and adjusted hazard ratios (HRs) with $95 \%$ CIs and $P$-values.

Treatment add-on was defined as the addition of one or more pharmacologic treatments to the index treatment, where 1) the index treatment and the add-on treatments were used concomitantly for at least 28 consecutive days and 2) the add-on treatments were not used for at least 60 consecutive days prior to the add-on date. The list of medications considered for treatment add-on comprised the following stimulants and nonstimulants: MPH, LDX (for the ATX cohort), ATX (for the LDX cohort), AMPH, guanfacine, and clonidine. Although only the extended-release formulation of guanfacine and clonidine is licensed for the treatment of ADHD (in the US), immediate release guanfacine and clonidine were also considered as they are recommended by guidelines. ${ }^{30}$

The treatments added to the index treatment are descriptively reported for the LDX and ATX cohorts. In addition, time to treatment add-on was analyzed using survival analyses, with event time defined as the number of days between the index date and the first date that another treatment was added to the index treatment. Patients' observation periods 
were censored if patients reached the date of treatment discontinuation or the end of the study period without a treatment add-on. Treatment add-on rates were estimated using Kaplan-Meier analyses and compared between cohorts using log-rank tests. Cox proportional-hazards models were used to compare the distribution of treatment add-ons between cohorts. Unadjusted and adjusted (adjust for differences in any discrepant baseline patient characteristics) results are reported as HRs with $95 \% \mathrm{CIs}$ and $P$-values.

DACON was defined as the ratio of 1) the number of units (tablets or capsules) of the index treatment dispensed during the study period and 2) the number of days of supply of the index treatment during the study period. DACON was calculated among the subgroup of patients with complete information available about the number of units dispensed and the number of days of supply. The proportion of patients with a DACON greater than 1 was compared between cohorts using logistic regression models, where the dependent variable was a binary variable indicating if the rounded DACON value was greater than 1 and the independent variable was a dichotomous variable to identify the patients' cohort. Multivariate regression models adjusted for differences in any discrepant baseline patient characteristics between cohorts. Results are reported as unadjusted and adjusted ORs with 95\% CI and $P$-values.

As MPH includes short- and long-acting formulations and the type of formulation prescribed may be endogenous to the patient's profile, all of the aforementioned analyses were replicated among a subgroup of patients who received long-acting MPH (including osmotic-release oral system $\mathrm{MPH}$ ) as first-line therapy.

The following variables were included in all multivariate regression models to adjust for differences in discrepant baseline patient characteristics between cohorts: demographics (age on the index date, sex, and region of residence), type of health care plan, Charlson comorbidity index score, year of the index date, and physical comorbidities that were significantly different between the cohorts and that had at least $5 \%$ prevalence in both cohorts (ie, hypertension).

All statistical analyses were conducted using SAS 9.3 statistical software (SAS Institute, Inc., Cary, NC, USA). Statistical significance was assessed based on a two-sided $\alpha$ error of 0.05 .

\section{Results}

A total of 3,392 patients met the inclusion criteria: 2,718 $(80.1 \%)$ were initiated on LDX as second-line therapy and $674(19.9 \%)$ were initiated on ATX in second-line therapy (Figure S1).
At the index date, patients in the LDX cohort were $\sim 2$ years younger than patients in the ATX cohort (31.5 versus 33.9 years; $P<0.001)$. Men comprised a little less than half of the study sample (45.7\%) and sex proportions were similar between cohorts $(P=0.137)$. The mean Charlson comorbidity index score during the baseline period was similar between the LDX cohort and the ATX cohort ( 0.154 versus 0.172 ; $P=0.366$ ). During the baseline period, fewer patients in the LDX cohort than in the ATX cohort had documented diagnoses for mood disorders (25.9\% versus $31.3 \%$ ), adjustment disorders (7.2\% versus $10.5 \%$ ), substance-related disorders (4.8\% versus $7.0 \%)$, hypertension $(6.1 \%$ versus $9.6 \%)$, and obesity $(2.1 \%$ versus $3.7 \%$; all $P<0.05)$ (Table 1 ; Table S1).

During the study period, patients in the LDX cohort had a higher mean adherence level to their index treatment than patients in the ATX cohort. Results were consistent based on both the PDC (0.48 versus 0.30$)$ and MPR (0.51 versus 0.32 ), and both unadjusted and adjusted mean differences were statistically significant. In particular, the adjusted mean differences in adherence levels were 0.18 and 0.19 for the PDC and MPR, respectively (both $P<0.001$ ). The adjusted mean difference represents $\sim 66$ days of coverage over a 12 -month period or $\sim 37.5 \%$ lower medication use for ATX compared with LDX (data not shown). Similarly, a greater proportion of patients in the LDX cohort than in the ATX cohort were adherent to their index treatment during the study period. Again, results were consistent for both the PDC (23.4\% versus $11.3 \%)$ and MPR (27.4\% versus $13.1 \%)$. Both unadjusted and adjusted ORs were statistically significant (all $P<0.001$ ). After adjusting for differences in characteristics between the cohorts, the probability of being adherent ( $P D C \geq 0.8$ ) was 2.61 times higher (adjusted OR: 2.61, 95\% CI: 2.01-3.38) in the LDX cohort compared with ATX cohort. Similarly, based on the MPR, the probability of being adherent (MPR $\geq 0.8$ ) was 2.73 times higher (adjusted OR: 2.73, 95\% CI: 2.14-3.49) in the LDX cohort compared with ATX cohort (Table 2).

The Kaplan-Meier estimate for treatment discontinuation at month 12 was significantly lower for the LDX cohort compared with ATX cohort (63.4\% versus 84.6\%; log-rank test $P<0.001)$. A high proportion of patients in the LDX and ATX cohorts $(25.7 \%$ versus $44.2 \%$; log-rank test $P<0.001)$ discontinued their index treatment within the first month of treatment initiation; that is, after only one prescription-fill for some patients. Among patients with a treatment discontinuation, most patients discontinued their treatment during the first 3 months of the study period in both the LDX and ATX 
Table I Comparison of patient characteristics

\begin{tabular}{|c|c|c|c|}
\hline Characteristic & LDX, N=2,7 I 8 & ATX, $N=674$ & $P$-value \\
\hline \multicolumn{4}{|l|}{ Demographics } \\
\hline Age on the index date, mean (SD), years & $31.5(12.7)$ & $33.9(13.4)$ & $<0.00 I^{\mathrm{a}}$ \\
\hline Male, n (\%) & $1,224(45.0)$ & $325(48.2)$ & 0.137 \\
\hline \multicolumn{4}{|l|}{ Region in the USA, n (\%) } \\
\hline Northeast & $439(16.2)$ & $159(23.6)$ & $<0.00 I^{a}$ \\
\hline Midwest & $674(24.8)$ & $175(26.0)$ & \\
\hline South & $1,262(46.4)$ & $199(29.5)$ & \\
\hline West & $296(10.9)$ & $129(19.1)$ & \\
\hline Unknown & $47(1.7)$ & $12(1.8)$ & \\
\hline \multicolumn{4}{|l|}{ Health plan, n (\%) } \\
\hline Preferred provider organization & $\mathrm{I}, 691(62.2)$ & $374(55.5)$ & $<0.00 I^{\mathrm{a}}$ \\
\hline Home maintenance organization & $360(13.2)$ & $127(18.8)$ & \\
\hline Point of service plan, without capitation & $244(9.0)$ & $52(7.7)$ & \\
\hline Consumer-driven health plan & $143(5.3)$ & $27(4.0)$ & \\
\hline High-deductible health plan & $60(2.2)$ & $9(1.3)$ & \\
\hline Comprehensive & $34(1.3)$ & II (I.6) & \\
\hline Exclusive provider organization & $28(1.0)$ & $5(0.7)$ & \\
\hline Point of service plan, with partial or full capitation & $18(0.7)$ & $3(0.4)$ & \\
\hline Unknown plan & $140(5.2)$ & $66(9.8)$ & \\
\hline \multicolumn{4}{|l|}{ Year of the index date, $\mathrm{n}(\%)$} \\
\hline 2009 & $66(2.4)$ & $15(2.2)$ & 0.817 \\
\hline 2010 & $768(28.3)$ & $202(30.0)$ & \\
\hline 2011 & $\mathrm{I}, 129(4 \mathrm{I} .5)$ & $270(40.1)$ & \\
\hline 2012 & $755(27.8)$ & I $87(27.7)$ & \\
\hline Charlson comorbidity index (CCl), mean (SD) & $0.154(0.591)$ & $0.172(0.622)$ & 0.366 \\
\hline $\mathrm{CCl}=0, \mathrm{n}(\%)$ & $2,428(89.3)$ & $594(88.1)$ & 0.371 \\
\hline $\mathrm{CCl} \geq \mathrm{I}, \mathrm{n}(\%)$ & $290(10.7)$ & $80(11.9)$ & \\
\hline \multicolumn{4}{|l|}{ Mental comorbid conditions, $\mathrm{n}(\%)^{\mathrm{b}}$} \\
\hline Mood disorders & $703(25.9)$ & $2 I I(31.3)$ & $0.004^{\mathrm{a}}$ \\
\hline Anxiety disorders & $530(19.5)$ & I5I (22.4) & 0.092 \\
\hline Adjustment disorders & $197(7.2)$ & $71(10.5)$ & $0.005^{\mathrm{a}}$ \\
\hline Substance-related disorders & $|3|(4.8)$ & $47(7.0)$ & $0.025^{\mathrm{a}}$ \\
\hline Sleep disorders & $93(3.4)$ & $31(4.6)$ & 0.145 \\
\hline \multicolumn{4}{|l|}{ Physical comorbid conditions, $\mathrm{n}(\%)^{\mathrm{b}}$} \\
\hline Hypertension & $167(6.1)$ & $65(9.6)$ & $0.00 \mathrm{I}^{\mathrm{a}}$ \\
\hline Chronic pulmonary disease & 147 (5.4) & $46(6.8)$ & 0.155 \\
\hline Hypothyroidism & $119(4.4)$ & $27(4.0)$ & 0.670 \\
\hline Deficiency anemias & $65(2.4)$ & $20(3.0)$ & 0.392 \\
\hline Obesity & $57(2.1)$ & $25(3.7)$ & $0.015^{\mathrm{a}}$ \\
\hline Diabetes, uncomplicated & $58(2.1)$ & $16(2.4)$ & 0.703 \\
\hline
\end{tabular}

Notes: aSignificant at the $5 \%$ level. No multiplicity adjustment was performed, and so the $P$-values need to be interpreted with caution; bonly comorbid conditions with at least $2 \%$ prevalence in both cohorts are reported; unless otherwise specified, all characteristics were measured during the 6-month baseline period.

Abbreviations: ATX, atomoxetine; LDX, lisdexamfetamine dimesylate; SD, standard deviation.

cohorts (59.6\% and $73.2 \%$ of discontinuations, respectively). After adjusting for differences in baseline patient characteristics between cohorts, patients in the LDX cohort had a risk of treatment discontinuation at month 12 that was $47 \%$ lower (adjusted HR: 0.53 , 95\% CI: $0.48-0.59, P<0.001$ ) than for patients in ATX cohort. Results were consistent at 1,3, and 6 months (all $P<0.001$ ) (Figure 1).

The Kaplan-Meier estimate for treatment add-on at month 3 was significantly lower for the LDX cohort compared with the ATX cohort (8.8\% versus $11.4 \%$; log-rank test
$P<0.05)$. However, the Kaplan-Meier estimates were not significantly different between cohorts at month $12(25.7 \%$ versus $24.9 \%$; log-rank test $P=0.297$ ). Cox proportionalhazards regression analysis yielded consistent results; after adjusting for differences in characteristics between cohorts, patients in the LDX cohort had a risk of treatment add-on at month 3 that was $27 \%$ lower (adjusted HR: $0.73,95 \% \mathrm{CI}$ : 0.54-0.98) than that for patients in ATX cohort $(P<0.05)$, but the HR was not statistically significant at month 12 (Figure 2). 
The most commonly used drugs for add-on treatment in the LDX cohort were short-acting AMPH (45.5\% of LDX patients receiving add-on treatment), long-acting AMPH (21.9\%), and short-acting MPH (11.8\%); the most commonly used drugs in the ATX cohort were short-acting AMPH (23.5\% of ATX patients receiving add-on treatment), longacting AMPH (21.0\%), and LDX (19.8\%) (Table S2).

A total of 3,363 patients ( $99.1 \%$ of the full sample) were selected for the DACON analysis: 2,697 in the LDX cohort and 666 in ATX cohort. A total of 13 patients were excluded because they had incomplete information available about the number of units dispensed or the number of days of supply, and 16 patients were excluded because they had an extreme DACON value $(>10)$, suggesting data-entry errors. Over the study period, patients in the LDX cohort had a mean DACON of 1.10 , with $94.2 \%$ of patients having a DACON equal to 1 . Patients in the ATX cohort had a mean DACON of 1.31, with $74.6 \%$ of patients having a DACON equal to 1 . After adjusting for differences in baseline patient characteristics between the cohorts, the likelihood of having a DACON greater than 1 was $80 \%$ lower (adjusted OR: $0.20,95 \%$ CI: 0.15-0.25) for patients in the LDX cohort compared with those in ATX cohort. Both unadjusted and adjusted ORs were statistically significant (both $P<0.001$ ) (Table 3 ).

A subgroup of 2,794 patients (82.4\%) were treated with long-acting MPH in first-line therapy: 2,283 (81.7\%) received LDX as second-line therapy and 511 (18.3\%) received ATX. Findings were consistent with those of the core analysis, both unadjusted and adjusted (Table S3).

\section{Discussion}

This retrospective cohort study of claims data compared treatment outcomes between adults with ADHD treated with either LDX or ATX in second-line therapy following first-line therapy with MPH. The study showed that LDX was associated with favorable treatment outcomes compared with ATX during the 12-month period following the initiation of second-line therapy. Specifically, patients treated with LDX were more adherent to their second-line therapy and had lower treatment discontinuation rates. Patients treated with LDX also had a lower DACON compared with those treated with ATX; however, ATX is indicated for both once- or twice-daily dosing, while LDX is only indicated for once-daily dosing. Finally, patients treated with LDX were less likely to be prescribed an add-on ADHD treatment during the first 3 months following the initiation of secondline therapy, but no statistically significant differences were found between the cohorts after 6 and 12 months. However, 


\begin{tabular}{lllll}
\hline Treatment discontinuation & Month 1 & Month 3 & Month 6 & Month 12 \\
\hline $\begin{array}{l}\text { LDX patients who had a treatment } \\
\text { discontinuation, } \mathrm{n}(\%)\end{array}$ & $699(25.7)$ & $1,027(37.8)$ & $1,406(51.7)$ & $1,724(63.4)$ \\
$\begin{array}{l}\text { ATX patients who had a treatment } \\
\text { discontinuation, } \mathrm{n}(\%)\end{array}$ & $298(44.2)$ & $417(61.9)$ & $521(77.3)$ & $570(84.6)$ \\
LDX, KM rates $(95 \% \mathrm{Cl})$ & & & & \\
ATX, KM rates $(95 \% \mathrm{Cl})$ & $25.7(24.1,27.4)$ & $37.8(36.0,39.6)$ & $51.7(49.9,53.6)$ & $63.4(61.6,65.2)$ \\
$\quad P$-value & $44.2(40.6,48.1)$ & $61.9(58.2,65.5)$ & $77.3(74.1,80.4)$ & $84.6(81.7,87.2)$ \\
Unadjusted: LDX/ATX, HR $(95 \% \mathrm{Cl})$ & $0.56(0.49,0.65)$ & $0.54(0.48,0.60)$ & $0.52(0.47,0.58)$ & $0.54(0.49,0.60)$ \\
$\quad P$-value & $<0.001^{*}$ & $<0.001^{*}$ & $<0.001^{*}$ & $<0.001^{*}$ \\
Adjusted: LDXIATX, HR $(95 \% \mathrm{Cl})$ & $0.56(0.49,0.65)$ & $0.54(0.48,0.60)$ & $0.52(0.47,0.58)$ & $0.53(0.48,0.59)$ \\
$\quad P$-value & $<0.001^{*}$ & $<0.001^{*}$ & $<0.001^{*}$ & $<0.001^{*}$ \\
\hline
\end{tabular}

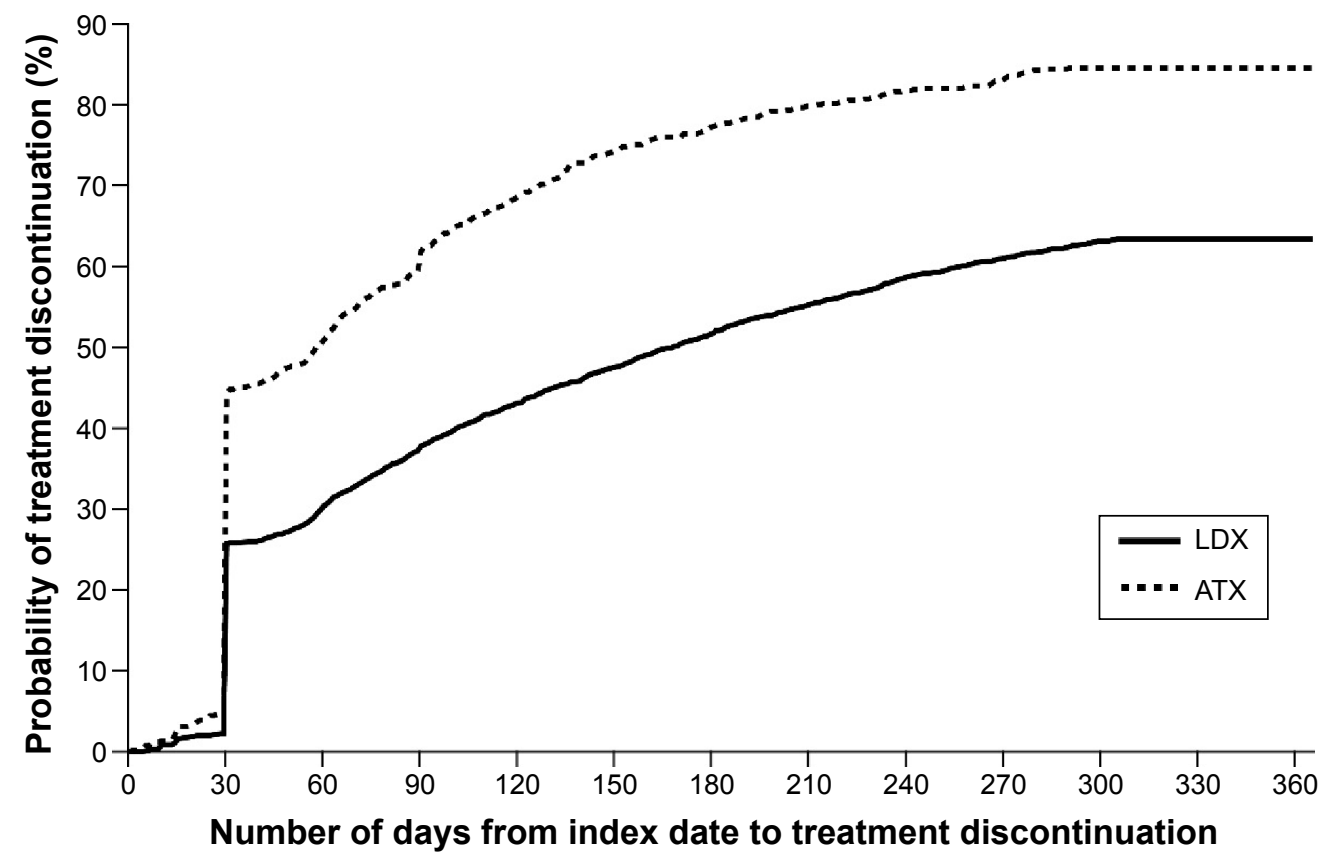

Figure I Kaplan-Meier estimates and hazard ratios for treatment discontinuation.

Notes: *Significant at the $5 \%$ level. No multiplicity adjustment was performed, so the $P$-values need to be interpreted with caution. Total number of LDX patients, $N=2,7 \mid 8$; Total number of ATX patients, $\mathrm{N}=674$.

Abbreviations: ATX, atomoxetine; Cl, confidence interval; KM, Kaplan-Meier; LDX, lisdexamfetamine dimesylate; HR, hazard ratio.

given that patients were censored at treatment discontinuation and that $\sim 63 \%$ and $85 \%$ of the LDX and ATX cohorts, respectively, discontinued their therapy over the study period, the number of patients at risk of treatment add-on might not have been sufficient to detect significant differences over the 12-month study period. The difference in add-on rates observed over the first 3-month period may be explained by the fact that ATX can require 4-6 weeks of treatment before significant improvements in symptom control are seen. ${ }^{53}$ Thus, physicians are more likely to prescribe another treatment in combination with ATX. All of the analyses were replicated among a subgroup of patients treated with either long-acting or osmotic-release oral system MPH in first-line therapy, and the findings for these subgroup analyses were consistent with those of the core analyses. According to a recent systematic literature review conducted by Gajria et $a 1,{ }^{42}$ there is little research regarding treatment outcomes (eg, adherence, discontinuation, add-on, DACON) in adults with ADHD. Nonetheless, a few studies have investigated different treatment outcomes among adults with ADHD receiving different therapies for the treatment of ADHD, including, among others, LDX and ATX. ${ }^{37-39,54,55}$ The findings of the current study are generally consistent with the results from those previous studies. However, as opposed to the current study, patients from the previous studies were not necessarily treated with MPH in first-line therapy and could have received several lines of therapy prior to the index date.

In 2013, Setyawan et $\mathrm{al}^{37}$ reported that adult patients treated with LDX in second or later lines of therapy were 


\begin{tabular}{|c|c|c|c|c|}
\hline Treatment add-on & Month 1 & Month 3 & Month 6 & Month 12 \\
\hline LDX patients who had a treatment add-on, n (\%) & $94(3.5)$ & $198(7.3)$ & $312(11.5)$ & $424(15.6)$ \\
\hline ATX patients who had a treatment add-on, n (\%) & $39(5.8)$ & $59(8.8)$ & $69(10.2)$ & $81(12.0)$ \\
\hline LDX, KM rates $(95 \% \mathrm{Cl})$ & $3.5(2.9,4.3)$ & $8.8(7.7,10.1)$ & $16.1(14.5,17.9)$ & $25.7(23.5,28.1)$ \\
\hline ATX, KM rates $(95 \% \mathrm{Cl})$ & $6.0(4.4,8.1)$ & $11.4(8.8,14.7)$ & $16.1(12.5,20.5)$ & $24.9(19.5,31.5)$ \\
\hline$P$-value & $0.004^{*}$ & $0.017^{*}$ & 0.192 & 0.297 \\
\hline Unadjusted: LDX/ATX, HR $(95 \% \mathrm{Cl})$ & $0.58(0.40,0.85)$ & $0.70(0.53,0.94)$ & $0.84(0.65,1.09)$ & $0.88(0.69,1.12)$ \\
\hline$P$-value & $0.005^{\star}$ & $0.018^{*}$ & 0.192 & 0.297 \\
\hline Adjusted: LDX/ATX, HR $(95 \% \mathrm{Cl})$ & $0.63(0.43,0.92)$ & $0.73(0.54,0.98)$ & $0.87(0.67,1.14)$ & $0.92(0.72,1.17)$ \\
\hline$P$-value & $0.018^{*}$ & $0.038^{*}$ & 0.304 & 0.490 \\
\hline
\end{tabular}

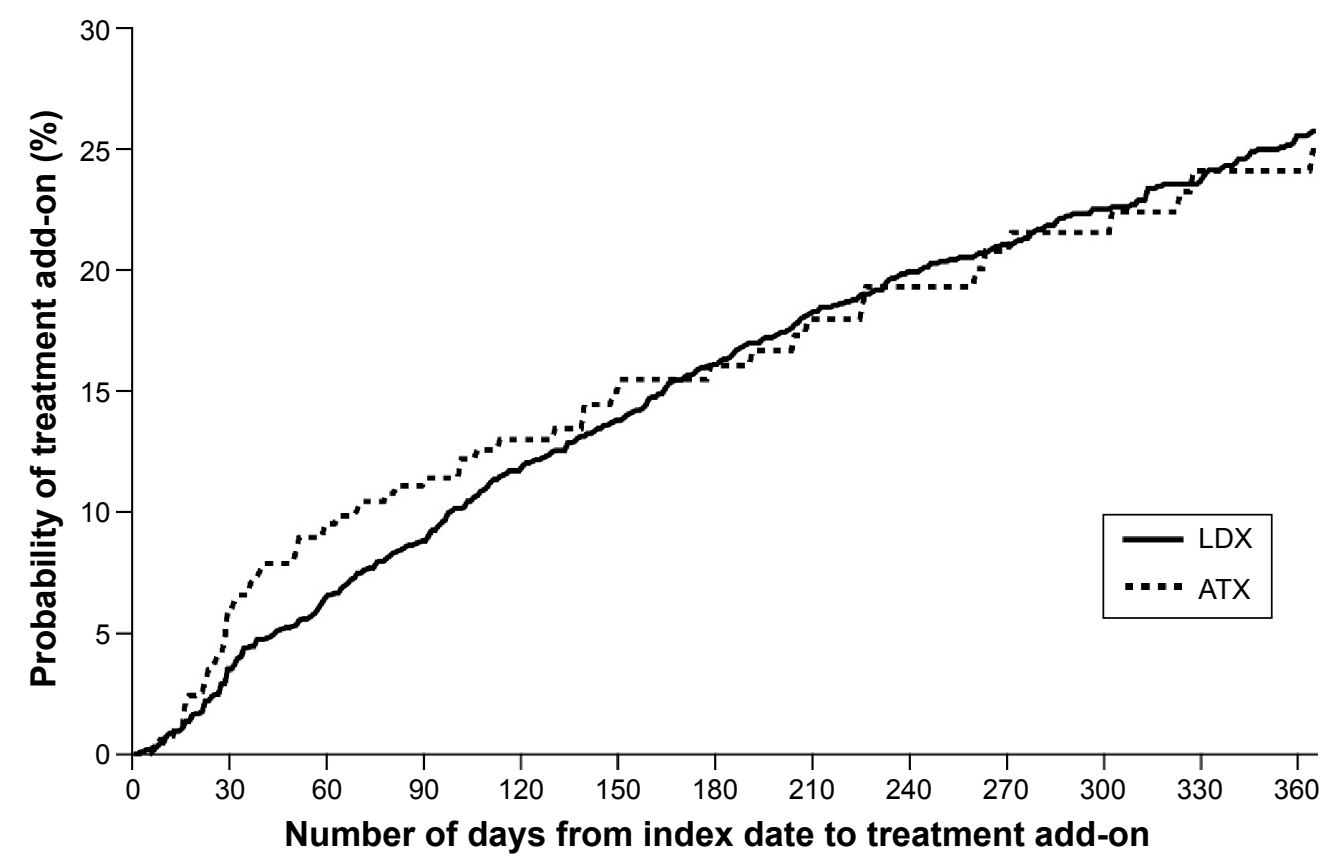

Figure 2 Kaplan-Meier estimates and hazard ratios for treatment add-on.

Notes: *Significant at the $5 \%$ level. No multiplicity adjustment was performed, so the $P$-values need to be interpreted with caution. Total number of LDX patients, $N=2,7$ I 8 ; Total number of ATX patients, $\mathrm{N}=674$.

Abbreviations: ATX, atomoxetine; Cl, confidence interval; KM, Kaplan-Meier; LDX, lisdexamfetamine dimesylate; HR, hazard ratio.

more adherent to their treatment than those treated with ATX. The Setyawan et $\mathrm{al}^{37}$ study and the current study found similar adherence levels, with a mean PDC in the LDX cohort of 0.48 in both studies, and a mean PDC in the ATX cohort of 0.31 in the Setyawan study and 0.30 in the current study. In both studies, patients receiving LDX were $\sim 50 \%-60 \%$ more adherent than those receiving ATX, and more than twice as likely to be adherent (defined as PDC $\geq 0.8$ in both studies). Although reasons for treatment nonadherence are not available in claims databases, low treatment adherence is known to be problematic in patients with ADHD due to many reasons, ${ }^{42}$ such as dosing inconvenience and patients' perception that the treatment is not needed. The extent of nonadherence warrants attention, since medication effectiveness and benefits rely on patients' adherence. ${ }^{28}$
The treatment discontinuation findings of the current study were also consistent with those reported in previously published studies, ${ }^{38,42,54,55}$ presenting consistently high discontinuation rates (or low persistence). A study from van den Ban et $\mathrm{a}^{55}$ evaluated the discontinuation of MPH and ATX among adult patients from the Netherlands and found that $80 \%$ of patients treated for ADHD discontinued their therapy (treatment gap of at least 90 days) within 12 months after initiation. Another study by Hodgkins et $a l^{54}$ conducted among patients newly treated with long-acting stimulants or ATX also found high discontinuation rates in adult patients receiving LDX or ATX; the median time to discontinuation (50\% of patients who discontinued) was 3.9 months among patients treated with LDX and 2.5 months among those treated with ATX. In a recent systematic literature review, Gajria et $\mathrm{l}^{42}$ also concluded that adults with ADHD had high 
Table 3 Comparison of DACON

\begin{tabular}{|c|c|c|}
\hline & $\begin{array}{l}\text { LDX, } \\
\mathrm{N}=2,697\end{array}$ & $\begin{array}{l}\text { ATX, } \\
N=666\end{array}$ \\
\hline $\mathrm{DACON}^{\mathrm{b}}$, mean (SD) & $1.10(0.77)$ & $\mathrm{I} .3 \mathrm{I}(0.82)$ \\
\hline DACON = I, n (\%) & $2,540(94.2)$ & $497(74.6)$ \\
\hline $\mathrm{DACON}=2, \mathrm{n}(\%)$ & $122(4.5)$ & I55 (23.3) \\
\hline $\mathrm{DACON}=3, \mathrm{n}(\%)$ & $17(0.6)$ & $7(1.1)$ \\
\hline $\mathrm{DACON}=4, \mathrm{n}(\%)$ & I $(0.0)$ & $3(0.5)$ \\
\hline $\mathrm{DACON} \geq 5, \mathrm{n}(\%)$ & $17(0.6)$ & $4(0.6)$ \\
\hline \multicolumn{3}{|l|}{ Patients with a DACON $>1$} \\
\hline $\mathrm{n}(\%)$ & $157(5.8)$ & $169(25.4)$ \\
\hline Unadjusted OR (95\% Cl): LDX/ATX & $0.18(0.14,0.23)$ & \\
\hline$P$-value & $<0.00 \mathrm{I}^{\mathrm{a}}$ & \\
\hline Adjusted OR (95\% Cl): LDX/ATX & $0.20(0.15,0.25)$ & \\
\hline$P$-value & $<0.001^{a}$ & \\
\hline
\end{tabular}

Notes: aSignificant at the $5 \%$ level. No multiplicity adjustment was performed, and so the $P$-values need to be interpreted with caution. ${ }^{b} \mathrm{DACON}$ value was rounded to the unit.

Abbreviations: ATX, atomoxetine; $\mathrm{Cl}$, confidence interval; DACON, daily average consumption; LDX, lisdexamfetamine dimesylate; OR, odds ratio; SD, standard deviation.

treatment discontinuation rates, and reported that the main reasons for treatment discontinuation were adverse events and ineffectiveness/suboptimal response.

Few studies have analyzed add-on treatment in adult patients with ADHD treated with LDX and ATX. A recent study from Setyawan et $\mathrm{al}^{39}$ compared the add-on treatment rates in adult patients with ADHD treated with LDX and other commonly prescribed stimulants in second or later lines of therapy. Over a 12-month period, the authors found that $20 \%$ of patients treated with LDX received an add-on treatment, and that patients treated with LDX had lower or nonsignificantly different add-on treatment rates compared with those treated with other commonly prescribed stimulants. However, the results from this previous study cannot be directly compared with those from the current study as treatment add-on rates were not assessed for patients treated with ATX and the authors used a slightly different definition of treatment add-on (ie, concomitant use of the index treatment and another ADHD medication for at least 28 days), which could also include treatment combinations.

Finally, DACONs in patients treated with LDX and ATX reported in a recent study by Hodgkins et a ${ }^{54}$ were consistent with those from the current study. Hodgkins et $\mathrm{a}^{54}$ analyzed the DACON of adult patients with ADHD newly treated with long-acting stimulants or ATX, and found a DACON of 1.06 in patients treated with LDX and 1.32 in patients treated with ATX, compared with 1.10 and 1.31, respectively, in the current study.

In summary, although previous studies s $^{37-39,42,54,55}$ and the current study had slightly different cohorts and outcome definitions, findings were fairly consistent in terms of their direction and magnitude. Overall, the results from the different studies showed that adult patients with ADHD treated with LDX experienced better treatment outcomes (based on treatment adherence, discontinuation, add-on, and DACON) compared with those treated with ATX.

This study provides a comprehensive comparison of treatment adherence, discontinuation, add-on, and DACON in adults with ADHD. This study confirms and reinforces the findings from previous studies with recent data by reporting consistent results, even though the current study was conducted with a slightly different population - that is, patients treated with either LDX or ATX in second-line therapy following the use of MPH in first-line therapy. Although several treatment options are available in the US for the treatment of adults with ADHD, few medications are licensed or available in Europe. A systematic literature review on the treatment options for adults with ADHD in Europe concluded that there is a lack of pharmacologic treatment options for this population, resulting in some patients being untreated or suboptimally treated ${ }^{44}$ For instance, while both MPH and AMPH are commonly prescribed in first-line therapy in the $\mathrm{US},{ }^{30} \mathrm{MPH}$ remains the only first-line agent recommended by the European guidelines at this time. ${ }^{43}$ The current study was performed on a US sample because of the unavailability of a large, real-world sample from European countries with adult ADHD patients treated with LDX. However, recent studies have shown that adult patients with ADHD from North America and Europe have similar demographic and disease characteristics, suggesting that outcomes from both populations may be similar. ${ }^{56,57}$ Therefore, the conclusions from the current study may also apply to a European population..$^{58}$ While this study may inform practice in Europe, further research is warranted to confirm the consistency of the findings in a European population.

\section{Limitations}

The present study is subject to some limitations. First, claims databases do not record disease severity, reasons for treatment nonadherence, or treatment changes, and other factors, such as patient lifestyle, education, occupation, or preference for stimulant versus nonstimulant medications, or physician prescribing behaviors, which can vary across patients and impact treatment outcomes. Information on patient symptoms and functional outcomes is also not available in claims databases. Therefore, treatment efficacy and patient symptoms were not assessed in the current study. 
Second, while multivariate models were applied to adjust for observed differences in characteristics between cohorts (eg, the ATX cohort had a higher prevalence of some comorbidities compared with the LDX cohort), some differences may have remained after multivariate regression adjustments, and differences in patients' profiles can still exist for unobserved characteristics and impact the outcome comparisons between cohorts. For instance, patients' or physicians' subjective preferences for stimulants versus nonstimulants might have impacted the cohort classification and treatment outcomes.

Third, claims databases are subject to coding errors, data omissions, and other misclassifications. However, these errors are unlikely to alter the conclusions, as they would be expected to affect both cohorts to a similar extent. Fourth, treatment outcomes were assessed based on the prescription filled; actual patient medication consumption could not be confirmed. Fifth, the current study focused on a broad sample of patients treated in the second-line with either LDX or ATX following MPH, but did not assess patients' specific treatment patterns or patients' cumulative exposure to MPH before initiating a second-line treatment, which may have impacted the outcome comparison between cohorts.

Finally, the current study focused on ADHD-indicated treatments in the US (with the exception of guanfacine and clonidine immediate release). However, previous studies on children and adolescents with ADHD have shown that the use of off-label treatment, such as antipsychotics, is common, ${ }^{59-62}$ which may have impacted some treatment outcomes, such as add-on treatment rates.

\section{Conclusion}

In conclusion, this study showed that patients treated with LDX in second-line therapy following treatment with MPH had higher treatment adherence, lower treatment discontinuation rates, and lower DACON compared with patients treated with ATX. Further research is needed to confirm the symptomatic and functional changes that might drive these treatment outcomes.

\section{Acknowledgments}

This research was funded by the sponsor, Shire Development LLC. Under the direction of the authors, Agnihotram Ramanakumar and Philippe Thompson-Leduc (employees of Analysis Group, funded by Shire Development LLC) provided writing and editorial assistance for this publication. Editorial assistance in formatting, proofreading, and copy editing the manuscript, and coordination and collation of comments was provided by Caudex, funded by Shire International GmbH. Sabrina Paillé and James Wu from Shire also reviewed the manuscript for scientific accuracy. Although employees of the sponsor were involved in the design, collection, analysis, interpretation, and fact checking of information, the content of this manuscript, interpretation of the data, and the decision to submit the manuscript for publication in Patient Preference and Adherence were made by the authors independently.

Some of the data from this paper have been presented in poster form at the 5th World Congress on ADHD, 28-31 May, 2015, Glasgow, Scotland. The abstract was published in ADHD Attention Deficit and Hyperactivity Disorders 2015;7 (Issue 1 Supplement):S1-S119.

\section{Disclosure}

Alain Joseph is an employee of Shire and owns stock/stock options. Vanja Sikirica was an employee of Shire at the time of this work. Martin Cloutier and Annie Guérin are employees of Analysis Group, Inc., which provides paid consultancy services to Shire. Roy Nitulescu is a former employee of Analysis Group. The authors report no other conflicts of interest in this work.

\section{References}

1. Spencer T, Biederman J, Wilens T. Nonstimulant treatment of adult attention-deficit/hyperactivity disorder. Psychiatr Clin North Am. 2004; 27(2):373-383.

2. Kooij SJ, Bejerot S, Blackwell A, et al. European consensus statement on diagnosis and treatment of adult ADHD: The European Network Adult ADHD. BMC Psychiatry. 2010;10:67.

3. Carotenuto M, Esposito MF, Di Pasquale FF, De Stefano S, Santamaria F. Psychological, cognitive and maternal stress assessment in children with primary ciliary dyskinesia. World J Pediatr. 2013;9(7):312-317.

4. Esposito M, Antinolfi LF, Gallai BF, et al. Executive dysfunction in children affected by obstructive sleep apnea syndrome: an observational study. Neuropsychiatr Dis Treat. 2013;9:1087-1094.

5. Esposito M, Gallai BF, Parisi LF, et al. Visuomotor competencies and primary monosymptomatic nocturnal enuresis in prepubertal aged children. Neuropsychiatr Dis Treat. 2013;9:921-926.

6. Esposito M, Gallai BF, Parisi LF, et al. Primary nocturnal enuresis as a risk factor for sleep disorders: an observational questionnaire-based multicenter study. Neuropsychiatr Dis Treat. 2013;9:437-443.

7. Esposito M, Carotenuto M. Intellectual disabilities and power spectra analysis during sleep: a new perspective on borderline intellectual functioning. J Intellect Disabil Res. 2014;58(5):421-429.

8. Esposito M, Carotenuto MF, Roccella M. Primary nocturnal enuresis and learning disability. Minerva Pediatr. 2011;63(2):99-104.

9. Esposito M, Carotenuto M. Borderline intellectual functioning and sleep: the role of cyclic alternating pattern. Neurosci Lett. 2010;485(2): 89-93.

10. Esposito M, Gallai B, Roccella M, et al. Anxiety and depression levels in prepubertal obese children: a case-control study. Neuropsychiatr Dis Treat. 2014;10:1897-1902.

11. Dueck A, Thome JF, Haessler F. The role of sleep problems and circadian clock genes in childhood psychiatric disorders. J Neural Transm (Vienna). 2012;119(10):1097-1104. 
12. Cabral P. Attention deficit disorders: are we barking up the wrong tree? Eur J Paediatr Neurol. 2006;10(2):66-77.

13. Kissling $\mathrm{C}$, Retz WF, Wiemann $\mathrm{S}$, et al. A polymorphism at the 3 '-untranslated region of the CLOCK gene is associated with adult attention-deficit hyperactivity disorder. Am J Med Genet B Neuropsychiatr Genet. 2008;147(3):333-338.

14. Xu X, Breen G, Chen C, Huang Y, Wu Y, Asherson P. Association study between a polymorphism at the 3 '-untranslated region of CLOCK gene and attention deficit hyperactivity disorder. Behav Brain Funct 2010;6:48.

15. Modestino EJ, Winchester J. A retrospective survey of childhood ADHD symptomatology among adult narcoleptics. J Atten Disord. 2013;17(7): 574-582.

16. Jaksa P. ADHD Fact Sheet. Available from: https://add.org/adhd-facts/. Accessed December 16, 2015.

17. Searight HR, Burke JM, Rottnek F. Adult ADHD: evaluation and treatment in family medicine. Am Fam Physician. 2000;62(9):2077-2086, 2091-2092.

18. The Mayo Clinic. Diseases and Conditions: Adult ADHD. Available from: http://www.mayoclinic.org/diseases-conditions/adultadhd/basics/definition/con-20034552?reDate $=01102015$. Accessed December 16, 2015.

19. Fayyad J, de Graaf R, Kessler R, et al. Cross-national prevalence and correlates of adult attention-deficit hyperactivity disorder. $\mathrm{Br} J$ Psychiatry. 2007;190:402-409.

20. Kessler RC, Adler L, Barkley R, et al. The prevalence and correlates of adult ADHD in the United States: results from the National Comorbidity Survey Replication. Am J Psychiatry. 2006;163(4):716-723.

21. Goodman DW. The consequences of attention-deficit/hyperactivity disorder in adults. J Psychiatr Pract. 2007;13(5):318-327.

22. Kendall T, Taylor E, Perez A, Taylor C. Diagnosis and management of attention-deficit/hyperactivity disorder in children, young people, and adults: summary of NICE guidance. BMJ. 2008;337:a1239.

23. Centers for Disease Control and Prevention. Attention-Deficit/Hyperactivity Disorder (ADHD). Available from: http://www.cdc.gov/ncbddd/ adhd/guidelines.html. Accessed December 16, 2015.

24. National Institute for Health and Care Excellence. Treatment for attention deficit hyperactivity disorder in adults: Choice of drug treatment Available from: http://goo.gl/emdNXQ. Accessed December 16 2015.

25. Dodson WW. Pharmacotherapy of adult ADHD. J Clin Psychol. 2005; 61(5):589-606.

26. Jain U, Hechtman L, Weiss M, et al. Efficacy of a novel biphasic controlled-release methylphenidate formula in adults with attention-deficit/hyperactivity disorder: results of a double-blind, placebo-controlled crossover study. J Clin Psychiatry. 2007;68(2): 268-277.

27. Kolar D, Keller A, Golfinopoulos M, Cumyn L, Syer C, Hechtman L. Treatment of adults with attention-deficit/hyperactivity disorder. Neuropsychiatr Dis Treat. 2008;4(2):389-403.

28. National Collaborating Centre for Mental Health. Attention deficit hyperactivity disorder: Diagnosis and management of ADHD in children, young people and adults. NICE clinical guideline 72. Available from: http://www.ncbi.nlm.nih.gov/books/NBK53652. Accessed December 16, 2015.

29. Nutt DJ, Fone K, Asherson P, et al. Evidence-based guidelines for management of attention-deficit/hyperactivity disorder in adolescents in transition to adult services and in adults: recommendations from the British Association for Psychopharmacology. J Psychopharmacol. 2007;21(1):10-41.

30. Seixas M, Weiss M, Muller U. Systematic review of national and international guidelines on attention-deficit hyperactivity disorder. J Psychopharmacol. 2012;26(6):753-765.

31. Arnold LE. Methylphenidate vs amphetamine: comparative review. J Atten Disord. 2000;3(4):200-211.

32. Spencer T, Biederman J, Wilens T, Harding M, O'Donnell D, Griffin S. Pharmacotherapy of attention-deficit hyperactivity disorder across the life cycle. J Am Acad Child Adolesc Psychiatry. 1996;35(4):409-432.
33. Reeves G, Schweitzer J. Pharmacological management of attentiondeficit hyperactivity disorder. Expert Opin Pharmacother. 2004;5(6): 1313-1320.

34. Vaughan B, Fegert J, Kratochvil CJ. Update on atomoxetine in the treatment of attention-deficit/hyperactivity disorder. Expert Opin Pharmacother. 2009;10(4):669-676.

35. Ramos-Quiroga JA, Montoya A, Kutzelnigg A, Deberdt W, Sobanski E. Attention deficit hyperactivity disorder in the European adult population: prevalence, disease awareness, and treatment guidelines. Curr Med Res Opin. 2013;29(9):1093-1104.

36. Himpel S, Banaschewski T, Heise CA, Rothenberger A. The safety of non-stimulant agents for the treatment of attention-deficit hyperactivity disorder. Expert Opin Drug Saf. 2005;4(2):311-321.

37. Setyawan J, Hodgkins P, Guerin A, et al. Comparing treatment adherence of lisdexamfetamine and other medications for the treatment of attention deficit/hyperactivity disorder: a retrospective analysis. $J$ Med Econ. 2013;16(7):962-975.

38. Setyawan J, Guerin A, Hodgkins P, et al. Treatment persistence in attention deficit/hyperactivity disorder: a retrospective analysis of patients initiated on lisdexamfetamine vs other medications. $J$ Med Econ. 2013;16(11):1275-1289.

39. Setyawan J, Hodgkins P, Guerin A, et al. Comparison of therapy augmentation and deviation rates from the recommended once-daily dosing regimen between LDX and commonly prescribed long-acting stimulants for the treatment of ADHD in youth and adults. JMed Econ. 2013;16(10):1203-1215.

40. Shaw M, Hodgkins $\mathrm{P}, \mathrm{Caci} \mathrm{H}$, et al. A systematic review and analysis of long-term outcomes in attention deficit hyperactivity disorder: effects of treatment and non-treatment. BMC Med. 2012;10:99.

41. Safren SA, Duran P, Yovel I, Perlman CA, Sprich S. Medication adherence in psychopharmacologically treated adults with ADHD. J Atten Disord. 2007;10(3):257-260.

42. Gajria K, Lu M, Sikirica V, et al. Adherence, persistence, and medication discontinuation in patients with attention-deficit/hyperactivity disorder - a systematic literature review. Neuropsychiatr Dis Treat. 2014; 10:1543-1569.

43. Banaschewski T, Coghill D, Santosh P, et al. Long-acting medications for the hyperkinetic disorders. A systematic review and European treatment guideline. Eur Child Adolesc Psychiatry. 2006;15(8):476-495.

44. Retz W, Retz-Junginger P, Thome J, Rosler M. Pharmacological treatment of adult ADHD in Europe. World J Biol Psychiatry. 2011; 12 Suppl 1:89-94.

45. Roskell NS, Setyawan J, Zimovetz EA, Hodgkins P. Systematic evidence synthesis of treatments for ADHD in children and adolescents: indirect treatment comparisons of lisdexamfetamine with methylphenidate and atomoxetine. Curr Med Res Opin. 2014;30(8):1673-1685.

46. Coghill D, Banaschewski T, Lecendreux M, et al. European, randomized, phase 3 study of lisdexamfetamine dimesylate in children and adolescents with attention-deficit/hyperactivity disorder. Eur Neuropsychopharmacol. 2013;23(10):1208-1218.

47. Childress AC, Sallee FR. The use of lisdexamfetamine dimesylate for the treatment of ADHD. Expert Rev Neurother. 2012;12(1):13-26.

48. What place for lisdexamfetamine in children and adolescents with ADHD? Drug Ther Bull. 2013;51(10):114-117.

49. Quan H, Sundararajan V, Halfon P, et al. Coding algorithms for defining comorbidities in ICD-9-CM and ICD-10 administrative data. Med Care. 2005;43(11):1130-1139.

50. American Psychiatric Association. Diagnostic and Statistical Manual of Mental Disorders, Fifth Edition (DSM-5). Arlington, VA: American Psychiatric Publishing; 2013.

51. Elixhauser A, Steiner C, Harris DR, Coffey RM. Comorbidity measures for use with administrative data. Med Care. 1998;36(1):8-27.

52. Yeaw J, Benner JS, Walt JG, Sian S, Smith DB. Comparing adherence and persistence across 6 chronic medication classes. J Manag Care Pharm. 2009;15(9):728-740.

53. Eli Lilly and Company. Starting Strattera. Available from: http://www. strattera.com/adult/starting-strattera.html. Accessed December 16, 2015. 
54. Hodgkins P, Sasane R, Christensen L, Erder H, Harley C. Persistence, augmentation, and consumption of long-acting medications in ADHD patients. Am J Pharm Benefits. 2012;4:e149-e158.

55. van den Ban E, Souverein PC, Swaab H, van Engeland H, Egberts TC, Heerdink ER. Less discontinuation of ADHD drug use since the availability of long-acting ADHD medication in children, adolescents and adults under the age of 45 years in the Netherlands. Atten Defic Hyperact Disord. 2010;2(4):213-220.

56. Schlander M, Schwarz O, Trott GE, Viapiano M, Bonauer N. Who cares for patients with attention-deficit/hyperactivity disorder(ADHD)? Insights from Nordbaden (Germany) on administrative prevalence and physician involvement in health care provision. Eur Child Adolesc Psychiatry. 2007;16(7):430-438.

57. Upadhyaya H, Adler LA, Casas M, et al. Baseline characteristics of European and non-European adult patients with attention deficit hyperactivity disorder participating in a placebo-controlled, randomized treatment study with atomoxetine. Child Adolesc Psychiatry Ment Health. 2013;7(1):14

58. Fridman M, Hodgkins PS, Kahle JS, Erder MH. Predicted effect size of lisdexamfetamine treatment of attention deficit/hyperactivity disorder (ADHD) in European adults: Estimates based on indirect analysis using a systematic review and meta-regression analysis. Eur Psychiatry. 2015;30(4):521-527.
59. Ben Amor L, Sikirica V, Cloutier M, et al. Combination and switching of stimulants in children and adolescents with attention deficit/ hyperactivity disorder in Quebec. J Can Acad Child Adolesc Psychiatry. 2014;23(3):157-166.

60. Lachaine J, De G, Sikirica V, et al. Treatment patterns, resource use, and economic outcomes associated with atypical antipsychotic prescriptions in children and adolescents with attention-deficit hyperactivity disorder in Quebec. Can J Psychiatry. 2014;59(11):597-608.

61. Sikirica V, Pliszka SR, Betts KA, et al. Comparative treatment patterns, resource utilization, and costs in stimulant-treated children with ADHD who require subsequent pharmacotherapy with atypical antipsychotics versus non-antipsychotics. J Manag Care Pharm. 2012;18(9): 676-689.

62. Sikirica V, Pliszka SR, Betts KA, et al. Impact of atypical antipsychotic use among adolescents with attention-deficit/hyperactivity disorder. Am J Manag Care. 2014;20(9):711-721. 


\section{Supplementary materials}

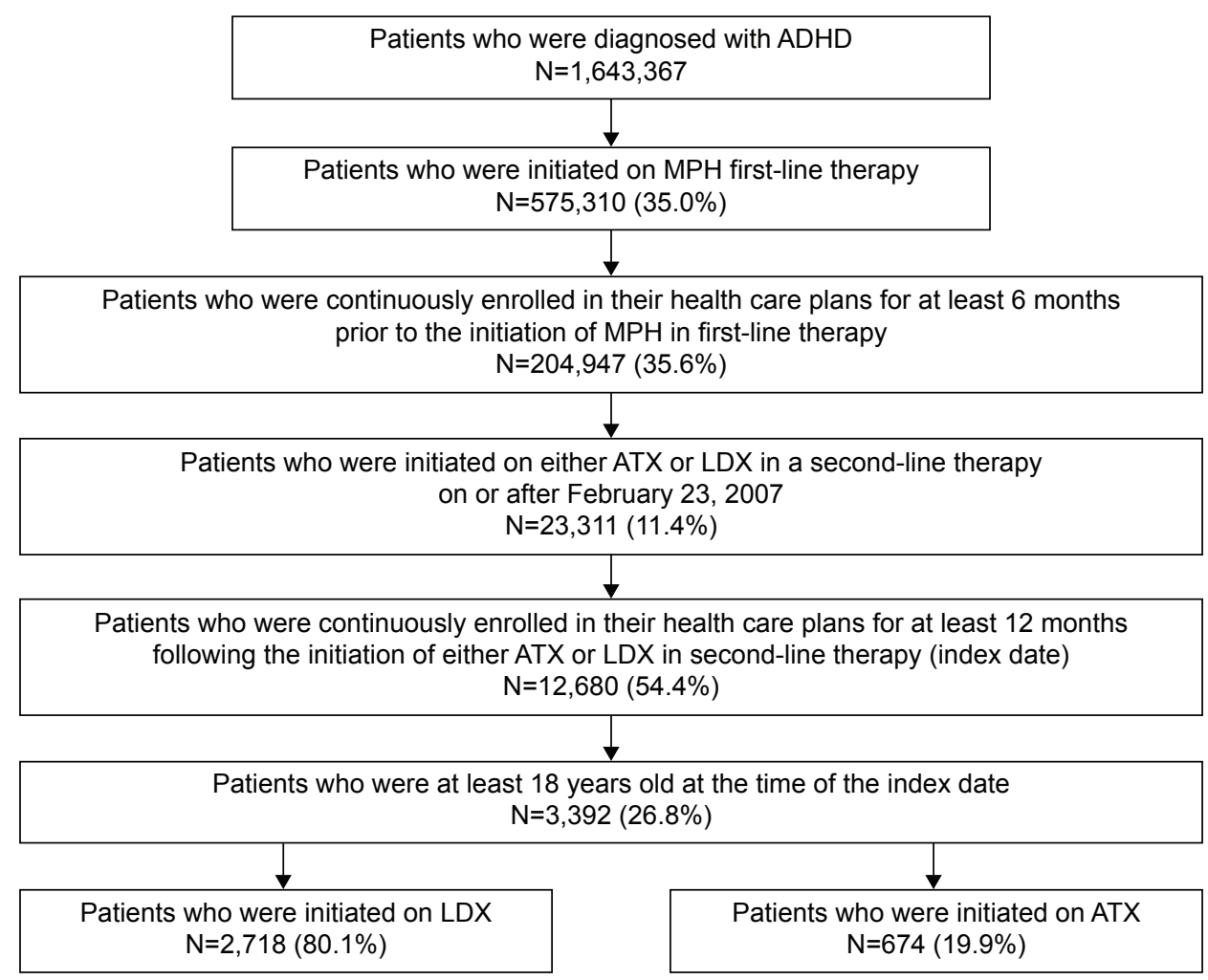

Figure SI Sample selection flow chart.

Abbreviations: ADHD, attention-deficit/hyperactivity disorder; MPH, methylphenidate; ATX, atomoxetine; LDX, lisdexamfetamine dimesylate.

Table SI Comparison of additional comorbid conditions

\begin{tabular}{|c|c|c|c|}
\hline Comorbid conditions & LDX patients, $\mathrm{N}=2,718$ & ATX patients, $N=674$ & $P$-value \\
\hline \multicolumn{4}{|l|}{ Mental comorbid conditions, $\mathrm{n}(\%)$} \\
\hline Disorders usually first diagnosed in infancy, childhood, or adolescence & $29(I . I)$ & II (I.6) & 0.224 \\
\hline Delirium, dementia, and amnestic and other cognitive disorders & $38(1.4)$ & $12(1.8)$ & 0.461 \\
\hline Substance-related disorders & $|3|(4.8)$ & $47(7.0)$ & $0.025^{\mathrm{a}}$ \\
\hline Schizophrenia and other psychotic disorders & II (0.4) & $8(1.2)$ & $0.015^{\mathrm{a}}$ \\
\hline Mood disorders & $703(25.9)$ & $211(31.3)$ & $0.004^{*}$ \\
\hline Anxiety disorders & $530(19.5)$ & $151(22.4)$ & 0.092 \\
\hline Somatoform disorders & $9(0.3)$ & $\mathrm{I}(0 . \mathrm{I})$ & 0.433 \\
\hline Factitious disorders & $0(0.0)$ & $0(0.0)$ & NA \\
\hline Dissociative disorders & I $(0.0)$ & $0(0.0)$ & NA \\
\hline Sexual and sex identity disorders & $40(1.5)$ & $10(1.5)$ & 0.982 \\
\hline Eating disorders & $13(0.5)$ & $5(0.7)$ & 0.399 \\
\hline Sleep disorders & $93(3.4)$ & $31(4.6)$ & 0.145 \\
\hline Impulse-control disorders not elsewhere classified & $7(0.3)$ & $6(0.9)$ & $0.017^{\mathrm{a}}$ \\
\hline Adjustment disorders & $197(7.2)$ & $7 I(10.5)$ & $0.005^{\mathrm{a}}$ \\
\hline Personality disorders (Axis II) & $10(0.4)$ & $4(0.6)$ & 0.414 \\
\hline Other conditions that may be a focus of clinical attention & $135(5.0)$ & $52(7.7)$ & $0.005^{\mathrm{a}}$ \\
\hline \multicolumn{4}{|l|}{ Physical comorbid conditions, n (\%) } \\
\hline Congestive heart failure & $0(0.0)$ & $\mathrm{I}(0.1)$ & NA \\
\hline Valvular disease & $25(0.9)$ & $3(0.4)$ & 0.223 \\
\hline Pulmonary circulation disorders & $2(0.1)$ & $2(0.3)$ & 0.131 \\
\hline
\end{tabular}


Table SI (Continued)

\begin{tabular}{|c|c|c|c|}
\hline Comorbid conditions & LDX patients, $\mathrm{N}=2,7$ I 8 & ATX patients, $N=674$ & $P$-value \\
\hline Peripheral vascular disorders & $2(0.1)$ & $2(0.3)$ & 0.131 \\
\hline Hypertension (uncomplicated and complicated) & $167(6.1)$ & $65(9.6)$ & $0.00 \mathrm{I}^{\mathrm{a}}$ \\
\hline Paralysis & $3(0.1)$ & $0(0.0)$ & NA \\
\hline Other neurologic disorders & $56(2.1)$ & $24(3.6)$ & $0.022^{\mathrm{a}}$ \\
\hline Epilepsy & $13(0.5)$ & $5(0.7)$ & 0.399 \\
\hline Chronic pulmonary disease & $147(5.4)$ & $46(6.8)$ & 0.155 \\
\hline Diabetes, uncomplicated & $58(2.1)$ & $16(2.4)$ & 0.703 \\
\hline Diabetes, complicated & $7(0.3)$ & $5(0.7)$ & 0.058 \\
\hline Hypothyroidism & $119(4.4)$ & $27(4.0)$ & 0.670 \\
\hline Renal failure & $3(0.1)$ & $0(0.0)$ & NA \\
\hline Liver disease & $16(0.6)$ & $3(0.4)$ & 0.655 \\
\hline Peptic ulcer disease, excluding bleeding & $0(0.0)$ & $0(0.0)$ & NA \\
\hline Acquired immune deficiency syndrome & $9(0.3)$ & $2(0.3)$ & 0.888 \\
\hline Lymphoma & $3(0.1)$ & $2(0.3)$ & 0.259 \\
\hline Metastatic cancer & $3(0.1)$ & $\mathrm{I}(0.1)$ & 0.797 \\
\hline Solid tumor, without metastasis & $18(0.7)$ & $6(0.9)$ & 0.527 \\
\hline Rheumatoid arthritis/collagen vascular diseases & $37(\mathrm{I} .4)$ & $13(1.9)$ & 0.274 \\
\hline Coagulopathy & $12(0.4)$ & $0(0.0)$ & NA \\
\hline Obesity & $57(2.1)$ & $25(3.7)$ & $0.015^{\mathrm{a}}$ \\
\hline Weight loss & $29(1.1)$ & $6(0.9)$ & 0.684 \\
\hline Fluid and electrolyte disorders & $25(0.9)$ & $10(1.5)$ & 0.195 \\
\hline Blood loss anemia & $2(0.1)$ & $I(0.1)$ & 0.559 \\
\hline Deficiency anemias & $65(2.4)$ & $20(3.0)$ & 0.392 \\
\hline
\end{tabular}

Notes: aSignificant at the $5 \%$ level. No multiplicity adjustment was performed, and so the $P$-values need to be interpreted with caution.

Abbreviations: ATX, atomoxetine; LDX, lisdexamfetamine dimesylate; NA, not applicable.

Table S2 Drugs used for add-on treatment

\begin{tabular}{lll}
\hline Drug used for add-on treatment & $\begin{array}{l}\text { LDX patients who had a } \\
\text { treatment add-on (N=424) }\end{array}$ & $\begin{array}{l}\text { ATX patients who had a } \\
\text { treatment add-on (N=8I) }\end{array}$ \\
\hline LDX & NA & $16(19.8)$ \\
ATX & $19(4.5)$ & NA \\
MPH SA & $50(11.8)$ & $9(11.1)$ \\
MPH LA & $41(9.7)$ & $15(18.5)$ \\
OROS MPH & $14(3.3)$ & $2(2.5)$ \\
AMPH SA & $193(45.5)$ & $19(23.5)$ \\
AMPH LA & $93(21.9)$ & $17(21.0)$ \\
Guanfacine (extended and immediate release) & $17(4.0)$ & $2(2.5)$ \\
Clonidine (extended and immediate release) & $7(1.7)$ & $2(2.5)$ \\
\hline
\end{tabular}

Notes: Frequencies are not mutually exclusive. Patients could have a treatment add-on with more than one drug. Data shown as $n$ (\%).

Abbreviations: AMPH, amphetamine; ATX, atomoxetine; LA, long-acting; LDX, lisdexamfetamine dimesylate; MPH, methylphenidate; NA, not applicable; OROS, osmotic-release oral system; SA, short-acting. 
Table S3 Selected findings for subgroup analysis

\begin{tabular}{|c|c|c|}
\hline Total number of patients in each group & LDX, $N=2,283$ & ATX, $N=5$ I I \\
\hline \multicolumn{3}{|l|}{ Treatment adherence, $\mathrm{PDC} \geq 0.8$} \\
\hline Adherent patients, n (\%) & $544(23.8)$ & $57(11.2)$ \\
\hline Unadjusted OR (95\% Cl): LDX/ATX & $2.49(1.86,3.34)$ & \\
\hline$P$-value & $<0.00 \mathrm{I}^{\mathrm{a}}$ & \\
\hline Adjusted OR (95\% Cl): LDX/ATX & $2.70(2.01,3.65)$ & \\
\hline$P$-value & $<0.00 \mathrm{I}^{\mathrm{a}}$ & \\
\hline \multicolumn{3}{|l|}{ Treatment discontinuation after 12 months } \\
\hline Patients with a treatment discontinuation, $\mathrm{n}(\%)$ & $1,428(62.5)$ & $434(84.9)$ \\
\hline Unadjusted HR (95\% Cl): LDX/ATX & $0.52(0.47,0.58)$ & \\
\hline$P$-value & $<0.00 \mathrm{I}^{\mathrm{a}}$ & \\
\hline Adjusted HR (95\% Cl): LDX/ATX & $0.5 \mathrm{I}(0.46,0.57)$ & \\
\hline$P$-value & $<0.00 \mathrm{I}^{\mathrm{a}}$ & \\
\hline \multicolumn{3}{|l|}{ Treatment add-on after 3 months } \\
\hline Patients with a treatment add-on, $\mathrm{n}(\%)$ & $161(7.1)$ & $44(8.6)$ \\
\hline Unadjusted HR (95\% Cl): LDX/ATX & $0.68(0.48,0.95)$ & \\
\hline$P$-value & $0.022^{\mathrm{a}}$ & \\
\hline Adjusted HR (95\% Cl): LDX/ATX & $0.70(0.49,0.98)$ & \\
\hline$P$-value & $0.037^{\mathrm{a}}$ & \\
\hline \multicolumn{3}{|l|}{ Treatment add-on after 12 months } \\
\hline Patients with a treatment add-on, $\mathrm{n}(\%)$ & $343(15.0)$ & $61(11.9)$ \\
\hline Unadjusted HR (95\% Cl): LDX/ATX & $0.83(0.63,1.10)$ & \\
\hline$P$-value & 0.191 & \\
\hline Adjusted HR (95\% Cl): LDX/ATX & $0.86(0.65,1.14)$ & \\
\hline$P$-value & 0.303 & \\
\hline Subgroup of patients with complete information about the number & LDX, $N=2,267$ & ATX, $\mathrm{N}=504$ \\
\hline \multicolumn{3}{|l|}{ of units dispensed and number of days of supply } \\
\hline Patients with a DACON >I, n (\%) & $|3|(5.8)$ & $132(26.2)$ \\
\hline Unadjusted OR (95\% Cl): LDX/ATX & $0.17(0.13,0.23)$ & \\
\hline$P$-value & $<0.00 \mathrm{I}^{\mathrm{a}}$ & \\
\hline Adjusted OR (95\% Cl): LDX/ATX & $0.19(0.14,0.24)$ & \\
\hline$P$-value & $<0.00 \mathrm{I}^{\mathrm{a}}$ & \\
\hline
\end{tabular}

Notes: aSignificant at the $5 \%$ level. No multiplicity adjustment was performed, and so the $P$-values need to be interpreted with caution.

Abbreviations: ATX, atomoxetine; CI, confidence interval; DACON, daily average consumption; HR, hazard ratio; LDX, lisdexamfetamine dimesylate; OR, odds ratio; PDC, proportion of days covered.

\section{Publish your work in this journal}

Patient Preference and Adherence is an international, peer-reviewed, open access journal that focuses on the growing importance of patient preference and adherence throughout the therapeutic continuum. Patient satisfaction, acceptability, quality of life, compliance, persistence and their role in developing new therapeutic modalities and compounds to optimize clinical outcomes for existing disease states are major areas of interest for the journal. This journal has been accepted for indexing on PubMed Central. The manuscript management system is completely online and includes a very quick and fair peer-review system, which is all easy to use. Visit http://www. dovepress.com/testimonials.php to read real quotes from published authors.

\footnotetext{
Submit your manuscript here: http://www.dovepress.com/patient-preference-and-adherence-journal
} 